\title{
Associations between access to farmers' markets and supermarkets, shopping patterns, fruit and vegetable consumption and health indicators among women of reproductive age in eastern North Carolina, USA
}

\author{
Stephanie B Jilcott Pitts ${ }^{1, *}$, Qiang Wu ${ }^{2}$, Jared T McGuirt ${ }^{3}$, Thomas W Crawford ${ }^{4}$, \\ Thomas C Keyserling ${ }^{5}$ and Alice S Ammerman ${ }^{6,7}$ \\ 'Department of Public Health, East Carolina University, 600 Moye Blvd, MS 660, Greenville, NC 27834, USA: \\ ${ }^{2}$ Department of Biostatistics, East Carolina University, Greenville, NC, USA: ${ }^{3}$ Department of Nutrition, University \\ of North Carolina at Chapel Hill, Chapel Hill, NC, USA: ${ }^{4}$ Department of Geography, East Carolina University, \\ Greenville, NC, USA: ${ }^{5}$ Department of Medicine, School of Medicine, University of North Carolina at Chapel \\ Hill, Chapel Hill, NC, USA: 'Department of Nutrition, Gillings School of Global Public Health, University of \\ North Carolina at Chapel Hill, Chapel Hill, NC, USA: ${ }^{7}$ Center for Health Promotion and Disease Prevention, \\ University of North Carolina at Chapel Hill, Chapel Hill, NC, USA
}

Submitted 18 0ctober 2012: Final revision received 3 April 2013: Accepted 11 April 2013: First published online 24 May 2013

\begin{abstract}
Objective: We examined associations between access to food venues (farmers' markets and supermarkets), shopping patterns, fruit and vegetable consumption and health indicators among women of reproductive age in eastern North Carolina, USA. Design: Access to food venues was measured using a Geographic Information System incorporating distance, seasonality and business hours, to quantify access to farmers' markets. Produce consumption was assessed by self-report of eating five or more fruits and vegetables daily. BMI and blood pressure were assessed by clinical measurements. Poisson regression with robust variance was used for dichotomous outcomes and multiple linear regression was used for continuous outcomes. As the study occurred in a university town and university students are likely to have different shopping patterns from non-students, we stratified analyses by student status.

Setting: Eastern North Carolina.

Subjects: Low-income women of reproductive age (18-44 years) with valid address information accessing family planning services at a local health department ( $n$ 400). Results: Over a quarter reported ever shopping at farmers' markets (114/400). A larger percentage of women who shopped at farmers' markets consumed five or more fruits and vegetables daily $(42 \cdot 1 \%)$ than those who did not $(24.0 \%$; $P<0 \cdot 001)$. The mean objectively measured distance to the farmers' markets where women reported shopping was $11 \cdot 4$ (SD 9.0) $\mathrm{km}(7 \cdot 1$ (SD 5.6) miles), while the mean distance to the farmers' market closest to the residence was $4 \cdot 0$ (SD $3 \cdot 7) \mathrm{km}$ (2.5 (sD 2.3) miles).

Conclusions: Among non-students, those who shopped at farmers' markets were more likely to consume five or more servings of fruits and vegetables daily. Future research should further explore potential health benefits of farmers' markets.
\end{abstract}

\author{
Keywords \\ Food environment \\ Obesity \\ Fruit and vegetable consumption
}

Improved access to food venues such as farmers' markets and supermarkets is commonly proposed as a strategy to address the obesity epidemic, as studies have shown that those who live closer to farmers' markets ${ }^{(1,2)}$ and supermarkets $^{(3,4)}$ generally have lower BMI than those who live further from such food venues ${ }^{(5,6)}$. The underlying assumption of such studies is that greater access to such food venues may lead to purchase and consumption of fresh produce. For example, Yoo et al. ${ }^{(7)}$ found that those who shop more frequently at supermarkets tended to have healthier diets when compared with those who shop less frequently at supermarkets. In a North Carolina-based study, we found that more frequent shopping at supermarkets was associated with healthier purchases among Supplemental Nutrition Assistance Program participants, when compared with those shopping at supermarkets less frequently ${ }^{(8)}$. Greater knowledge about associations between access to food venues, shopping frequency and 
food purchases is needed to inform future efforts to increase access to healthy foods.

Furthermore, much of the research regarding the food environment has involved objective measures of the food environment via Geographical Information Systems $(\mathrm{GIS})^{(1-4)}$, while some posit that perceptions of the food environment have a greater impact on shopping choices/ behaviours than objective measures ${ }^{(9-11)}$. In particular, an understudied aspect of food venue access, particularly important for quantifying access to farmers' markets, is 'accommodation', which includes the business hours a particular venue is open, seasonal schedules and other factors that may affect both perceived and objectively measured access to the food venue ${ }^{(12)}$. One group of researchers incorporated business hours to objectively measure food venue access, and found that those who consumed fruit more frequently had greater access to greengrocers (venues selling fruits and vegetables) that had longer hours of operation ${ }^{(13)}$. Among Hispanic women in New York City, the presence of a farmers' market in women's neighbourhoods was associated with greater fruit and vegetable consumption ${ }^{(14)}$. Another group examined seasonality and access to farmers' markets in New York State and found that higher-poverty census block groups had greater objectively measured access to produce markets during the summer months, but less access to such markets during the spring and winter months, when compared with all block groups ${ }^{(15)}$. In the field of geography, researchers have used time and distance functions to create accessibility indices $^{(16,17)}$, yet these techniques have not been widely used in the field of public health. This approach lends itself to exploring how objective space and time accessibility measures are associated with use of farmers' markets, fruit and vegetable consumption and health.

Learning about individuals' food shopping patterns and the locations where they shop will help facilitate more accurate assessments of true food environment exposures $^{(18,19)}$. Not much is known about shopping patterns and frequencies, the distance individuals are willing to travel to purchase foods ${ }^{(18,19)}$. One study found that the mean distance travelled to supermarkets was $7 \cdot 5 \mathrm{~km}(4 \cdot 67$ miles) ${ }^{(19)}$, while a recent review of the literature indicated that individuals travel $9 \cdot 7-27 \cdot 4 \mathrm{~km}$ (6-17 miles) to farmers' markets ${ }^{(20)}$. It is unknown whether individuals tend to shop at the food venues closest to their home or whether they travel past the closest venue to shop at another venue, perhaps due to more competitive prices, wider selection or other factors. Such knowledge is important because, in a previous study, those who travelled further to the grocery store had higher $\mathrm{BMI}^{(21)}$. Determining individuals' 'food activity spaces', or the geographic locations and variety of food venues at which individuals shop, is also important for future epidemiological studies of associations between food access and health.

Therefore, the purpose of the current study was to examine associations between access to food venues (farmers' markets and supermarkets), shopping patterns and health indicators among low-income women of reproductive age in eastern North Carolina. It is important to learn about such women's access to and use of healthy food venues, as low-income populations may be less likely to shop at farmers' markets than their higher-income counterparts ${ }^{(20)}$. Low-income women of reproductive age are also at increased risk of chronic disease ${ }^{(22)}$ and shopping at healthy food venues may help ameliorate this risk. In one study of health behaviours among a nationally representative sample of women of reproductive age, women with a history of gestational diabetes and with children in the household had significantly lower odds of consuming at least five servings of fruits and vegetables daily, compared with those with a history of gestational diabetes not living with children ${ }^{(23)}$.

In the current study, we examined associations between objectively measured access to food venues (farmers' markets and supermarkets), frequency of shopping at venues and health indicators (e.g. fruit and vegetable consumption, BMI and blood pressure). Objectively measured access included: (i) distance to the closest food venue to the residential location; (ii) mean distance travelled to the food venues where women reported shopping (visited food venue); and (iii) a novel indicator of space and time accessibility to farmers' markets, incorporating distance, seasonality and business hours. We hypothesized that better access to supermarkets and farmers' markets would be associated with more frequent shopping and more favourable health indicators. As perceived access to food venues may be more important than objectively measured access $^{(9-11)}$, we also examined the association between perceived and objectively measured access. Finally, we examined the mean distance travelled to food venues and further explored whether the mean distance travelled to food venues varied by rural/urban residence.

\section{Experimental methods}

\section{Study setting}

The present study was conducted in Pitt County, eastern North Carolina, USA (population estimate $=168148$ ). Pitt County is a primarily rural county, with a small urban centre as its county seat, which is home to a large regional medical centre and a large public university. According to the US Food Environment Atlas ${ }^{(24)}, 35 \cdot 9 \%$ of Pitt County adults are obese, and $4.25 \%$ of Pitt County households without a vehicle live more than $1.6 \mathrm{~km}$ ( 1 mile) from a supermarket.

\section{Participants}

The present study was conducted ancillary to the InShape (Integrated Screening and Health Assessment, Prevention and Evaluation) Study, the primary purpose of which was to examine risk factors for heart disease among women of 
reproductive age. Participants were recruited from the Title $\mathrm{X}$ federally funded family planning clinic at the local health department. Eligibility criteria were: female, age 18-44 years, English speaking, attending an initial or annual family planning visit, and having valid address information. Eligible women were invited by a research assistant to take part in the study. If interested, the women reviewed and signed informed consent and were given an enrolment questionnaire to complete, which included demographic and health-related questions, as well as questions addressing access to food venues and shopping patterns. Health indicator data were obtained by chart review of clinical measurements and completed questionnaires, as described below. The study was approved and monitored by the University of North Carolina Institutional Review Board.

\section{Perceived distance to food venues}

Perceived distance to farmers' markets and supermarkets was assessed by asking 'How far from your home is the (farmers' market/supermarket) where the primary shopper in your household does most of the shopping?' Participants were asked to provide responses in both minutes and miles.

\section{Objectively measured access to food venues}

Participants' home addresses were obtained via self-report and geocoded as point locations. Local farmers' markets were identified from the NC Farm Fresh website (www. ncfarmfresh.com), a state-sponsored clearinghouse of market information. Field staff verification supplemented the information obtained from this website, and farmers' market locations and hours were verified via telephone. Supermarkets were identified from the Reference USA business listings according the North American Industry Classification System (NAICS)/Standard Industrial Classification (SIC). The 2012 NAICS code (which replaced SIC codes in 1997) used for supermarkets (excluding convenience stores) was 445110 (SIC code 541101). Resulting listings were downloaded as Excel spreadsheets containing business name and latitude/longitude coordinates. A GIS point data layer of all supermarkets was created using ArcGIS version 10 software based on the coordinate information. Locations of each market were verified by examining corporate website listings and visual inspection using Google Maps to ensure that points were located at the proper location. In selected instances, spatial data editing was required to shift a point to its true location. Farmers' markets and supermarkets were also geocoded as points.

The road network distance from participant residences to a designated food venue was calculated (in miles) for every participant-farmers' market and participantsupermarket pair using ArcGIS Network Analyst, yielding variables measuring distances from participant residences to the closest farmers' market and supermarket. Women were given a list of all farmers' markets and supermarkets in the county and asked to indicate the food venues at which they most frequently shopped. The mean of all objectively measured distances to the farmers' markets/ supermarkets where women reported shopping (visited farmers' market and supermarket) were calculated using a SAS function, which calculates driving distance using Google's Application Programming Interface.

\section{Novel measure of access to farmers' markets}

Accessibility to farmer's markets was measured using techniques that incorporate both distance and time. It was assumed that greater distances to markets reflect less accessibility. Conversely, it was assumed that greater numbers of hours open for business reflect greater accessibility. To incorporate temporal accessibility of farmers' markets relative to supermarkets, it was assumed that all supermarkets were open $365 \mathrm{~d}$ per year for an average of $12 \mathrm{~h}$ per day $(4380 \mathrm{~h})$. The temporal component for farmers' market accessibility was quantified as the proportion of farmers' market annual hours relative to supermarket annual hours and used as a weight potentially ranging from $0 \cdot 0$ to $1 \cdot 0$. A proportion value of 0.25 indicates that a farmers' market is open for business $25 \%$ of the time that supermarkets are open throughout the year. There were thirteen farmers' markets in our study area, with time proportions ranging from $0 \cdot 01$ to $0 \cdot 48$ and a mean of $0 \cdot 20$. The accessibility measure is formally defined as:

$$
A_{i}=\sum_{j} \frac{t_{j}}{d_{i j}^{\beta}},
$$

where $A_{i}=$ farmers' market accessibility of participant $i$, $j=$ farmers' market $j, t_{j}=$ time proportion of open hours relative to supermarkets weight for farmers' market $j, \mathrm{~d}_{i j}=$ distance in network miles from participant $i$ to farmers' market $j$ and $\beta=$ distance decay exponent.

An interpretation of $A_{i}$ is that participants located close to farmers' markets with many open business hours have greater accessibility than participants located distant from markets with few open hours. The choice of the $\beta$ exponent reflects the importance of distance. A higher $\beta$ exponent means that the effect of distance is non-linear and accessibility decreases more rapidly with increasing distance to markets. Two different accessibility measures using $\beta=1$ and $\beta=2$ were created for analyses with an interest in assessing the effects of accessibility and sensitivity of results to the distance decay exponent $\beta$. Note that for $\beta=0, A_{i}$ would simply be the sum of all $t_{j}$ values, and accessibility would be identical for all participants. Both measures were rescaled to range from 0 to 100 using the linear $\mathrm{min} / \mathrm{max}$ technique. Because supermarkets are open year-round during normal business hours, we did not apply the novel measure of accessibility to supermarkets.

\section{Shopping frequency}

Shopping frequencies were assessed by asking 'How often do you or the primary food shopper in your 
household shop for food at a (farmers' market/supermarket)?' Response options were: never, a few times per year, once per month, 2-3 times per month, one time per week, and 2 or more times per week. Due to the distribution of responses, frequencies were dichotomized into 'never' and 'ever' (a few times per year or more) for farmers' markets and into 'low' ( $\leq 2-3$ times/month) and 'high' ( $\geq 1$ time/week) for supermarkets.

\section{Health indicators}

Fruit and vegetable consumption was assessed by chart review, using the most recent response to a single questionnaire item, asked during the family planning visit, indicating whether the participant self-reported eating five or more fruits and vegetables daily. BMI, weight in kilograms divided by the square of height in metres, systolic blood pressure (SBP) and diastolic blood pressure (DBP) measures were obtained by chart review of clinical measurements obtained at the family planning clinic visit. The fruit and vegetable consumption item came from a form used for clinical care and is typically completed at the initial family planning visit and updated periodically. Thus, the fruit and vegetable item may have been completed during a visit prior to the day of enrolment, whereas BMI, SBP and DBP were measured on the day of enrolment.

\section{Covariates}

Covariates included race, age, smoking status, education level and/or student status, rural/urban residence, car ownership and physical activity. Race was obtained from chart abstraction and was categorized into black, white and other. Age in years was calculated based upon date of birth and enrolment into the study. Smoking status was ascertained by asking if participants had smoked at least one cigarette in the last month. Education level was selfreported and dichotomized into less than $v$. greater than or equal to high-school graduation. Participants were asked to provide student and employment status. Urban residents were those with a Greenville or Winterville zip code, and rural residents were those with any other Pitt County zip code. Car ownership was ascertained by asking participants whether they leased or owned a car (yes/no). Physical activity was ascertained via self-reported number of minutes per week spent on vigorous and moderate physical activity, with min/week calculated by doubling the number of minutes for vigorous activity and adding this to moderate activity minutes. Because it seemed women over-reported their physical activity, in statistical modelling women were categorized as inactive (no physical activity), insufficiently active (some but $<150 \mathrm{~min} /$ week) or active ( $\geq 150 \mathrm{~min} /$ week).

\section{Statistical analyses}

We examined participant characteristics using descriptive statistics (means, frequencies) and examined differences between those who did and did not shop at farmers' markets using $t$ tests and $\chi^{2}$ tests. Poisson regression with robust variance was used for dichotomous outcomes ${ }^{(25)}$ and multiple linear regression was used for continuous outcomes, controlling for race, age, smoking status, education level, rural/urban residence, car ownership and physical activity.

Specifically, we examined associations between health indicators, shopping frequencies and objectively measured: (i) mean (road network) distance to the farmers' markets where women shopped (visited farmers' market); (ii) distance to the closest farmers' market; (iii) mean distance to the supermarkets where women shopped (visited supermarket); and (iv) distance to the closest supermarket, adjusting for race, age, smoking status, education level, rural/urban residence, car ownership and physical activity. We also examined associations between the novel measure of accessibility to farmers' markets (incorporating distance and seasonality) described above, frequency of farmers' market shopping and health indicators. We used the $\beta=1$ accessibility variables as these variables had more variability than the $\beta=2$ variables. We examined cross-sectional bivariate associations between perceived and objectively measured distance to the closest farmers' market and supermarket using Pearson's correlation coefficients. We examined mean objectively measured distances to farmers' market/supermarket from residential locations, with analyses stratified by urban/rural residence. A large state university and a community college are located in the town where the study was conducted. We learned from our formative work that many women seen in the family planning clinic were university or community college students. Students may have different shopping patterns from non-students, as they may live in dorms and eat in dining halls more often and thus not shop at farmers' markets and supermarkets as frequently. Therefore, analyses were stratified by student status, as we expected students would have different shopping patterns and/or health indicators from non-students. As non-independence of the data due to clustering of participants may have been an issue in our data, we calculated the intra-class correlation coefficient for BMI and blood pressures among women in the same zip code. As the intra-class correlation coefficient for BMI was $0 \cdot 020$, and the intra-class correlation coefficient for blood pressure was nearly zero, we felt that the non-independence due to clustering was negligible and therefore did not use mixed models. All analyses were conducted using the statistical software package SAS version $9 \cdot 2$.

\section{Results}

\section{Participant characteristics}

Among the 462 InShape participants, 400 had valid home addresses and comprise the sample for the present study. 
Table 1 Characteristics of all participants and of subgroups who did/did not shop at farmers' markets, with $P$ values for differences between subgroups: low-income women of reproductive age (18-44 years), Pitt County, eastern North Carolina, USA

\begin{tabular}{|c|c|c|c|c|c|c|c|}
\hline \multirow[b]{2}{*}{ Characteristic } & \multicolumn{2}{|c|}{$\begin{array}{l}\text { All participants } \\
\qquad(n \text { 400) }\end{array}$} & \multicolumn{2}{|c|}{$\begin{array}{l}\text { Participants who did not shop } \\
\text { at farmers' markets } \\
(n \text { 286) }\end{array}$} & \multicolumn{2}{|c|}{$\begin{array}{l}\text { Participants who shopped at } \\
\text { farmers' markets } \\
(n 114)\end{array}$} & \multirow{2}{*}{$\begin{array}{l}P \text { value for difference } \\
\text { between those who } \\
\text { shopped and did not shop } \\
\text { at farmers' markets }\end{array}$} \\
\hline & Mean & SD & Mean & SD & Mean & SD & \\
\hline Race (\% black) & \multicolumn{2}{|c|}{$63 \cdot 82$} & \multicolumn{2}{|c|}{$69 \cdot 01$} & \multicolumn{2}{|c|}{$50 \cdot 88$} & 0.001 \\
\hline Age (years) & $26 \cdot 32$ & $6 \cdot 28$ & $25 \cdot 83$ & $6 \cdot 04$ & $27 \cdot 56$ & $6 \cdot 73$ & 0.018 \\
\hline Education (\% below high-school graduate) & \multicolumn{2}{|c|}{$43 \cdot 58$} & \multicolumn{2}{|c|}{$43 \cdot 46$} & \multicolumn{2}{|c|}{$43 \cdot 86$} & 0.943 \\
\hline Student (\% yes) & \multirow{2}{*}{\multicolumn{2}{|c|}{$\begin{array}{l}39 \cdot 00 \\
15 \cdot 75\end{array}$}} & \multirow{2}{*}{\multicolumn{2}{|c|}{$\begin{array}{l}42 \cdot 66 \\
14 \cdot 69\end{array}$}} & \multicolumn{2}{|c|}{$29 \cdot 82$} & 0.018 \\
\hline Rural residence (\% rural) & & & & & \multirow{2}{*}{\multicolumn{2}{|c|}{$\begin{array}{l}18 \cdot 42 \\
74 \cdot 34\end{array}$}} & 0.364 \\
\hline Car ownership (\% own or lease a car) & \multicolumn{2}{|c|}{68.09} & \multicolumn{2}{|c|}{$65 \cdot 61$} & & & 0.097 \\
\hline Physical activity (min/week) & \multirow{2}{*}{\multicolumn{2}{|c|}{$29 \cdot 22$}} & \multirow{2}{*}{\multicolumn{2}{|c|}{$24.03^{500 \cdot 9}$}} & \multirow{2}{*}{\multicolumn{2}{|c|}{$42 \cdot 11$}} & $0 \cdot 198$ \\
\hline Eat five or more F\&V daily (\% yes) & & & & & & & $<0.001$ \\
\hline Mean BMI $\left(\mathrm{kg} / \mathrm{m}^{2}\right)$ & $29 \cdot 78$ & $8 \cdot 10$ & $29 \cdot 89$ & $8 \cdot 33$ & $29 \cdot 51$ & $7 \cdot 52$ & $0 \cdot 659$ \\
\hline Mean SBP $(\mathrm{mmHg})$ & $118 \cdot 0$ & $12 \cdot 51$ & $118 \cdot 2$ & $12 \cdot 12$ & $117 \cdot 6$ & $13 \cdot 51$ & 0.656 \\
\hline Mean DBP (mmHg) & $75 \cdot 02$ & $9 \cdot 27$ & $75 \cdot 10$ & $8 \cdot 91$ & $74 \cdot 82$ & $10 \cdot 16$ & 0.796 \\
\hline \multicolumn{8}{|c|}{ Mean objectively measured distance to the closest supermarket } \\
\hline $\mathrm{km}$ & 3.54 & 3.09 & $3 \cdot 56$ & $3 \cdot 12$ & 3.49 & 2.99 & 0.839 \\
\hline miles & $2 \cdot 20$ & 1.92 & $2 \cdot 21$ & 1.94 & $2 \cdot 17$ & $1 \cdot 86$ & 0.839 \\
\hline \multicolumn{8}{|c|}{ Mean objectively measured distance to the closest farmers' market } \\
\hline $\mathrm{km}$ & 3.97 & $3 \cdot 64$ & $3 \cdot 68$ & $3 \cdot 57$ & $4 \cdot 28$ & $3 \cdot 78$ & 0.280 \\
\hline miles & $2 \cdot 47$ & $2 \cdot 26$ & $2 \cdot 29$ & $2 \cdot 22$ & $2 \cdot 66$ & $2 \cdot 35$ & 0.280 \\
\hline \multicolumn{8}{|c|}{ Mean objectively measured distance to visited supermarket } \\
\hline $\mathrm{km}$ & 8.66 & $11 \cdot 79$ & $8 \cdot 64$ & $13 \cdot 47$ & $8 \cdot 70$ & $6 \cdot 02$ & 0.956 \\
\hline Miles & $5 \cdot 38$ & $7 \cdot 33$ & $5 \cdot 37$ & $8 \cdot 37$ & $5 \cdot 41$ & $3 \cdot 74$ & 0.956 \\
\hline \multicolumn{8}{|c|}{ Mean objectively measured distance to visited farmers' market } \\
\hline $\mathrm{km}$ & - & - & - & _ & $11 \cdot 47$ & $9 \cdot 03$ & \\
\hline miles & - & - & - & - & $7 \cdot 13$ & $5 \cdot 61$ & \\
\hline
\end{tabular}

F\&V, fruits and vegetables; SBP, systolic blood pressure; DBP, diastolic blood pressure.

Categorical variables are displayed as percentages, and continuous variables are displayed as mean and standard deviation 
Table 2 Associations between daily fruit and vegetable consumption (dependent variable) and shopping patterns and access to food venues (independent variables): low-income women of reproductive age (18-44 years), Pitt County, eastern North Carolina, USA

\begin{tabular}{|c|c|c|c|}
\hline Independent variable & Adjusted prevalence ratio & $95 \% \mathrm{Cl}$ & $P$ value \\
\hline Farmers' market shopping (never $v$. ever) & $1 \cdot 26$ & $0 \cdot 92,1 \cdot 71$ & $0 \cdot 147$ \\
\hline Non-students & 1.51 & $1 \cdot 03,2 \cdot 22$ & 0.036 \\
\hline Students & 0.96 & $0.57,1 \cdot 65$ & $0 \cdot 894$ \\
\hline Supermarket shopping (high v. low) & 1.01 & $0 \cdot 73,1 \cdot 38$ & 0.976 \\
\hline Non-students & 0.91 & $0 \cdot 60,1 \cdot 37$ & 0.643 \\
\hline Students & 1.09 & $0 \cdot 65,1 \cdot 80$ & $0 \cdot 750$ \\
\hline Distance to closest farmers' market & $1 \cdot 02$ & $0 \cdot 94,1 \cdot 10$ & $0 \cdot 704$ \\
\hline Non-students & $1 \cdot 00$ & $0 \cdot 91,1 \cdot 10$ & 0.976 \\
\hline Students & $1 \cdot 06$ & $0 \cdot 92,1 \cdot 20$ & $0 \cdot 410$ \\
\hline Distance to closest supermarket & $1 \cdot 02$ & $0 \cdot 94,1 \cdot 11$ & $0 \cdot 704$ \\
\hline Non-students & 1.00 & $0 \cdot 90,1 \cdot 11$ & 0.951 \\
\hline Students & 1.07 & $0.93,1.23$ & 0.382 \\
\hline Distance to visited farmers' market & 0.97 & $0.91,1.03$ & $0 \cdot 332$ \\
\hline Non-students & 0.97 & $0.90,1.04$ & 0.338 \\
\hline Students & 0.93 & $0 \cdot 78,1 \cdot 10$ & $0 \cdot 362$ \\
\hline Distance to visited supermarket & 1.01 & $1 \cdot 00,1.02$ & $0 \cdot 142$ \\
\hline Non-students & $1 \cdot 02$ & $0.95,1.08$ & 0.661 \\
\hline Students & 1.01 & $1 \cdot 00,1 \cdot 03$ & 0.085 \\
\hline Novel measure of access to farmers' markets & $1 \cdot 00$ & $0.96,1.02$ & 0.394 \\
\hline Non-students & 0.99 & $0.96,1.03$ & 0.677 \\
\hline Students & 0.97 & $0.91,1.04$ & $0 \cdot 304$ \\
\hline
\end{tabular}

Those who did not have a valid home address (and were thus not geocoded) were more likely to be rural residents than those with a valid home address who were geocoded $(P<0 \cdot 001)$. Of these, $114(28 \%)$ reported visiting at least one farmers' market on the list. Table 1 shows characteristics of all study participants and the subgroups of those who did and did not shop at a farmers' market. Briefly, the mean age of participants was 26 (SD 6) years, $64 \%$ were black, 39\% were students, 16\% lived in rural areas, $29 \%$ ate five or more fruits and vegetables daily, the mean BMI was 30 (SD 8) $\mathrm{kg} / \mathrm{m}^{2}$, the mean SBP was 118 (SD 13) mmHg and the mean DBP was 75 (SD 9) mmHg. Also, those who shopped at farmers' markets were older on average $(P=0 \cdot 018)$, less likely to be black $(P=0 \cdot 001)$ and less likely to be students $(P=0 \cdot 018)$, compared with those who did not shop at farmers' markets. Of note, $42 \cdot 1 \%$ of those who shopped at a farmers' market ate five or more fruits and vegetables daily, compared with $24.0 \%$ of those who did not shop at farmers' markets $(P<0 \cdot 001)$.

\section{Objectively measured access to food venues (farmer's markets and supermarkets), frequency of shopping at venues and bealtb indicators}

Among non-students, controlling for covariates, those who shopped at farmers' markets were more likely to consume five or more fruit and vegetables daily (adjusted relative risk $=1 \cdot 51,95 \% \mathrm{CI} 1 \cdot 03,2 \cdot 22 ; P=0 \cdot 036$ ), compared with those who did not shop at farmers' markets. There were no other statistically significant associations between daily fruit and vegetable consumption and shopping patterns or access to food venues (Table 2). Associations between shopping patterns and BMI or blood pressure were not statistically significant. Among students, those who had higher farmers' market accessibility (using the novel measure of access) were less likely to shop at a farmers' market (adjusted relative risk for students $=0 \cdot 89,95 \%$ CI $0 \cdot 82,0 \cdot 98 ; P=0 \cdot 006)$.

Among all participants, adjusting for all covariates, the association between SBP and average distance travelled to supermarkets approached statistical significance $(B=0 \cdot 17$, $95 \%$ CI $0.00,0.34 ; P=0 \cdot 055)$. In stratified, adjusted analyses, there was no association between distance to supermarkets and SBP among non-students; but among students, lower SBP was associated with closer average distance travelled to supermarkets $(B=0 \cdot 20,95 \%$ CI $0 \cdot 02$, $0 \cdot 38 ; P=0 \cdot 031$; data not shown).

\section{Perceived and objectively measured distances to the closest food venue}

The correlation between perceived distance to the farmers' market where women shopped and the objectively measured mean distance to the farmers' market where they reported shopping was $r=0.378(P<0 \cdot 001, n 98)$. The correlation between perceived distance to the supermarket where women shopped and the objectively measured mean distance to the supermarket where they reported shopping was $r=0 \cdot 135(P=0 \cdot 012, n 342)$.

\section{Distance travelled to food venues}

Table 3 shows mean objectively measured distances to farmers' markets and supermarkets where women reported shopping (visited market) and mean objectively measured GIS distances to markets closest to the residential address, with analyses stratified by urban/rural residence. The mean objectively measured distance to 
Table 3 Mean distances from residential address to the farmers' market and supermarket where women reported shopping (visited markets), and mean distances to the closest farmers' market and supermarket, by urban/rural residential status: low-income women of reproductive age (18-44 years), Pitt County, eastern North Carolina, USA

\begin{tabular}{|c|c|c|c|c|c|}
\hline & \multicolumn{4}{|c|}{$\begin{array}{l}\text { Mean objectively measured distance from home to (visited) farmers' market } \\
\text { where participants shop }\end{array}$} & \multirow{3}{*}{$\begin{array}{l}P \text { value for testing rural } v \\
\text { urban difference }\end{array}$} \\
\hline & \multicolumn{2}{|c|}{$\mathrm{km}$} & \multicolumn{2}{|c|}{ miles } & \\
\hline & Mean & SD & Mean & SD & \\
\hline All women $(n 114)$ & $11 \cdot 4$ & $9 \cdot 0$ & $7 \cdot 1$ & $5 \cdot 6$ & $<0.001$ \\
\hline Rural (n 21) & $20 \cdot 6$ & $11 \cdot 3$ & $12 \cdot 8$ & $7 \cdot 0$ & \\
\hline \multirow[t]{4}{*}{ Urban ( $n$ 93) } & $9 \cdot 5$ & $7 \cdot 1$ & $5 \cdot 9$ & $4 \cdot 4$ & \\
\hline & \multicolumn{4}{|c|}{$\begin{array}{l}\text { Mean objectively measured distance from home to (visited) supermarket } \\
\text { where participants shop }\end{array}$} & \\
\hline & \multicolumn{2}{|c|}{$\mathrm{km}$} & \multicolumn{2}{|c|}{ miles } & \\
\hline & Mean & SD & Mean & SD & \\
\hline All women ( $n$ 393) & $8 \cdot 7$ & $11 \cdot 7$ & $5 \cdot 4$ & $7 \cdot 3$ & $<0.001$ \\
\hline Rural $(n 59)$ & $13 \cdot 4$ & $6 \cdot 3$ & $8 \cdot 3$ & 3.9 & \\
\hline \multirow[t]{4}{*}{ Urban ( $n$ 334) } & $7 \cdot 9$ & $12 \cdot 4$ & $4 \cdot 9$ & $7 \cdot 7$ & \\
\hline & \multicolumn{4}{|c|}{ Mean objectively measured distance from home to closest farmers' market } & \\
\hline & \multicolumn{2}{|c|}{$\mathrm{km}$} & \multicolumn{2}{|c|}{ miles } & \\
\hline & Mean & SD & Mean & SD & \\
\hline All women $(n$ 400) & $4 \cdot 0$ & $3 \cdot 7$ & $2 \cdot 5$ & $2 \cdot 3$ & $<0.001$ \\
\hline Rural (n 63) & $7 \cdot 1$ & $5 \cdot 5$ & $4 \cdot 4$ & $3 \cdot 4$ & \\
\hline \multirow[t]{4}{*}{ Urban $(n$ 337) } & $3 \cdot 4$ & $2 \cdot 9$ & $2 \cdot 1$ & $1 \cdot 8$ & \\
\hline & \multicolumn{4}{|c|}{ Mean objectively measured distance from home to closest supermarket } & \\
\hline & \multicolumn{2}{|c|}{$\mathrm{km}$} & \multicolumn{2}{|c|}{ miles } & \\
\hline & Mean & SD & Mean & SD & \\
\hline All women $(n$ 400) & $3 \cdot 5$ & $3 \cdot 1$ & $2 \cdot 2$ & $1 \cdot 9$ & 0.006 \\
\hline Rural (n 63) & $4 \cdot 8$ & $4 \cdot 0$ & $3 \cdot 0$ & $2 \cdot 5$ & \\
\hline Urban ( $n$ 337) & $3 \cdot 4$ & $2 \cdot 9$ & $2 \cdot 1$ & $1 \cdot 8$ & \\
\hline
\end{tabular}

the farmers' markets where women reported shopping was $11 \cdot 4(\mathrm{sD} 9 \cdot 0) \mathrm{km}(7 \cdot 1$ ( $\mathrm{sD} 5 \cdot 6)$ miles) and the mean objectively measured distance to the farmers' market closest to the residential address was $4 \cdot 0$ (SD 3.7) $\mathrm{km}$ $(2 \cdot 5$ (sD $2 \cdot 3)$ miles). The mean objectively measured distance to the supermarkets where the woman reported shopping was $8 \cdot 7(\mathrm{SD} 11 \cdot 7) \mathrm{km}(5 \cdot 4$ (SD 7.3) miles) and the mean objectively measured distance to the supermarket closest to the residential address was $3 \cdot 5$ (SD 3.1) $\mathrm{km}$ $(2 \cdot 2$ (SD 1.9) miles).

\section{Discussion}

In our study sample, among non-students, shopping at a farmers' market was associated with increased likelihood of consuming five or more fruits and vegetables daily. Our cross-sectional study finding is in agreement with two recent longitudinal pilot studies ${ }^{(26,27)}$, one of which suggested that fruit and vegetable consumption increased upon introduction of a farm stand in Austin, Texas ${ }^{(26)}$.
The other found that farmers' market customers in Los Angeles, California reported they ate more fruits and vegetables due to new neighbourhood farmers' markets ${ }^{(27)}$. This work collectively supports the notion that improved access to and shopping at farmers' markets is associated with dietary behaviours.

It is noteworthy that the association between farmers' market shopping and likelihood of consuming five or more fruits and vegetables daily held true among nonstudents, but not among students. In the present study where most students attended a large university, food shopping patterns are likely to differ substantially from those of non-students. Specifically, most college students are likely to be on a school meal plan, wherein they purchase meals on campus, compared with non-students who typically purchase food from community food venues such as restaurants, supermarkets and farmers' markets. In addition, many students who live in dormitories or small apartments may not have food preparation and storage facilities that are conducive to shopping and preparing meals at home (or in a dormitory room). More work 
should be done to examine if these findings hold true in other university towns, and whether women who are college students are more likely to obtain food from such university-based sources. If so, perhaps interventions to incorporate farmers' markets on university campuses should be considered.

However, our findings did not confirm an association between distance to farmers' markets or supermarkets and BMI, as found in previous studies ${ }^{(1-6)}$, and we found no evidence that use of farmers' markets is associated with the two health indicators studied (BMI and SBP). This may be due to the fact that these two outcomes are very distal from the primary exposure of food venue shopping, and perhaps fruit and vegetable consumption and other dietary measures are more appropriate outcomes for this type of study. We did find among students that lower SBP was associated with closer average distance travelled to supermarkets. While it could be that better access to supermarkets leads to greater consumption of fruits and vegetables and lower blood pressure, it is likely that this finding is due to chance, as there were no other associations between access to supermarkets and blood pressure.

In our study we used a novel indicator of access, or accommodation, which accounted for the distance from home to the farmers' market, as well as seasonality and business hours. Counter-intuitively, among students, those who shopped at farmers' markets had lower farmers' market accessibility than those who did not shop at farmers' markets. This indicates that farmers' market shoppers may be motivated by factors other than distance when deciding to patronize a farmers' market, and thus distance to food venues may not be the best indicator or predictor of shopping behaviour or consumption. The correlation between perceived and objectively measured distance to farmers' markets was moderate $(0.38)$ while the correlation between perceived and objectively measured distance to supermarkets was low $(0 \cdot 14)$, suggesting that women are better at judging distance to farmers' markets $v$. supermarkets. While a prior Atlanta-based study found that the mean distance travelled to supermarkets was $7.6 \mathrm{~km}(4.7 \text { miles })^{(19)}$, we found the individuals travelled, on average, $8.7 \mathrm{~km}(5.4$ miles $)$ to their primary supermarket. This is a larger distance than the objectively measured $3.5 \mathrm{~km} \mathrm{(2.2} \mathrm{miles)} \mathrm{to} \mathrm{the} \mathrm{supermarket} \mathrm{closest}$ to women's residential addresses. The mean objectively measured distance to the farmers' markets where the woman reported shopping was $11 \cdot 4 \mathrm{~km}(7 \cdot 1$ miles $)$ in our study, which is similar to results of the recent review which indicated that individuals travel $9 \cdot 7-27 \cdot 4 \mathrm{~km}(6-17$ miles) to farmers' markets ${ }^{(20)}$. Again, this distance is larger than the objectively measured $4.0 \mathrm{~km}$ ( 2.5 miles) to the farmers' market closest to women's residential addresses. This is noteworthy, as women in our study travelled much further than the 1.6 or $3.2 \mathrm{~km}$ ( 1 or 2 mile) buffers typically used to quantify the food environment, suggesting that methods of measurement of food environment exposure should include women's actual food activity spaces. In addition, as expected, rural women travelled much further to food venues than their urban counterparts, suggesting that rural dwellers' food activity spaces are much larger than urban dwellers'.

The present study was limited by its cross-sectional design, as we cannot determine whether the independent variable (e.g. farmers' market shopping frequency) preceded the dependent variable (e.g. fruit and vegetable consumption). The study is also limited by the small sample size, especially for the subgroup analysis of students $v$. non-students. Google's Application Programming Interface likely contains error, and there may be systematic bias in the group of women who were not geocoded. Those who were not geocoded (because they did not have a valid home address) were more likely to be rural residents than those with a valid home address who were geocoded. The measure of fruit and vegetable consumption was dichotomous, based on self-reported data that may not be current as it was obtained from chart review of a form that may have been completed at a prior clinic visit. In addition, all types of food, healthy and unhealthy options, are available at supermarkets ${ }^{(28)}$. Despite these limitations, strengths of the study include the use of objective measures of distance to food venues women actually reported using $v$. those closest to the home address. Finally, we used a novel method to account for seasonality and business hours of farmers' markets, contributing to a quantification of the nebulous construct of accommodation ${ }^{(12)}$.

As distances to venues where woman reported shopping were larger than the distance to the closest venue, future research should more accurately define the neighbourhood food environment and factors determining shopping patterns. In the present study, among non-students, we found a positive association between shopping at farmers' markets and eating five or more fruits and vegetables daily. This association should be evaluated in future research using more robust study designs, including longitudinal studies that examine the use of farmers' markets and fruit and vegetable consumption among probability samples of community residents.

\section{Acknowledgements}

Sources of funding: Research reported in this publication was supported by Cooperative Agreement Number 5U48DP001944 from the Centers for Disease Control and Prevention (CDC) and by the National Institutes of Health/National Cancer Institute (NIH/NCI) under award number 5R03CA155362-02. The findings and conclusions in this report are those of the authors and do not necessarily represent the official position of the CDC or $\mathrm{NIH} / \mathrm{NCI}$. This research was also supported by resources 
from East Carolina University's Center for Geographic Information Science. Conflict of interest: The authors have no conflicts of interest to disclose. Authors' contributions: S.B.J.P. conceptualized and led the study, including guiding data collection, management, analysis and reporting, as well as led manuscript writing. Q.W. led data analysis and helped to draft the manuscript and revise it for intellectual content. J.T.M., T.W.C., T.C.K. and A.S.A. helped with study conceptualization and also helped to draft the manuscript and revise it for intellectual content. Acknowledgements: The authors are grateful to Cheryl Robbins, PhD, MS for manuscript review and to Ashley Ronay for her help in ascertaining farmers' market locations and business hours. They are thankful for data collection assistance from Nadya Majette, MPH and Jessica Sisneros, MS, RD. They are also grateful to the study participants who provided a deeper understanding of their interactions with the food environment.

\section{References}

1. Rundle A, Neckerman KM, Freeman L et al. (2009) Neighborhood food environment and walkability predict obesity in New York City. Environ Health Perspect 117, 442-447.

2. Jilcott SB, Wade S, McGuirt JT et al. (2011) The association between the food environment and weight status among eastern North Carolina youth. Public Health Nutr 14, $1610-1617$.

3. Morland KB \& Evenson KR (2009) Obesity prevalence and the local food environment. Health Place 15, 491-495.

4. Morland K, Diez Roux AV \& Wing S (2006) Supermarkets, other food stores, and obesity: the atherosclerosis risk in communities study. Am J Prev Med 30, 333-339.

5. Spence JC, Cutumisu N, Edwards J et al. (2009) Relation between local food environments and obesity among adults. BMC Public Health 9, 192.

6. Babey S, Diamant A \& Hastert T (2008) Designed for Disease: The Link between Local Food Environments and Obesity and Diabetes. California Center for Public Health Advocacy, PolicyLink, and the UCLA Center for Health Policy Research. http://www.policylink.org/atf/cf/\%7B97c6d565-bb43-406da6d5-eca3bbf35af0\%7D/DESIGNEDFORDISEASE_FINAL.PDF (accessed May 2013).

7. Yoo S, Baranowski T, Missaghian M et al. (2006) Foodpurchasing patterns for home: a grocery store-intercept survey. Public Health Nutr 9, 384-393.

8. Jilcott Pitts SB, McGuirt J, Carr LC et al. (2012) Associations between body mass index, shopping behaviors, amenity density, and characteristics of the neighborhood food environment among female adult Supplemental Nutrition Assistance Program (SNAP) participants in eastern North Carolina. Ecol Food Nutr 51, 1-16.

9. Moore LV, Diez Roux AV \& Brines S (2008) Comparing perception-based and Geographic Information System (GIS)-based characterizations of the local food environment. J Urban Health 85, 206-216.

10. Caspi CE, Kawachi I, Subramanian SV et al. (2012) The relationship between diet and perceived and objective access to supermarkets among low-income housing residents. Soc Sci Med 75, 1254-1262.

11. Gustafson AA, Sharkey J, Samuel-Hodge CD et al. (2011) Perceived and objective measures of the food store environment and the association with weight and diet among low-income women in North Carolina. Public Health Nutr 14, 1032-1038.

12. Caspi CE, Sorensen G, Subramanian SV et al. (2012) The local food environment and diet: a systematic review. Health Place 18, 1172-1187.

13. Thornton LE, Crawford DA \& Ball K (2010) Neighborhoodsocioeconomic variation in women's diet: the role of nutrition environments. Eur J Clin Nutr 64, 1423-1432.

14. Park Y, Quinn J, Florez K et al. (2011) Hispanic immigrant women's perspective on healthy foods and the New York City retail food environment: a mixed-method study. Soc Sci Med 73, 13-21.

15. Widener MJ, Metcalf SS \& Bar-Yam Y (2011) Dynamic urban food environments a temporal analysis of access to healthy foods. Am J Prev Med 41, 439-441.

16. Goldsberry K, Duvall CS, Howard PH et al. (2010) Visualizing nutritional terrain: a geospatial analysis of pedestrian produce accessibility in Lansing, Michigan, USA. Geocarto Int 25, 485-499.

17. Weber J \& Kwan M (2010) Bringing time back in: a study on the influence of travel time variations and facility opening hours on individual accessibility. Prof Geogr 54, 226-240.

18. Lytle LA (2009) Measuring the food environment: state of the science. Am J Prev Med 36, 4 Suppl., S134-S144.

19. Kerr J, Frank L, Sallis JF et al. (2012) Predictors of trips to food destinations. Int J Behav Nutr Phys Act 9, 58.

20. Byker C, Shanks J, Misyakc S et al. (2012) Characterizing farmers' market shoppers: a literature review. J Hunger Environ Nutr 7, 38-52.

21. Inagami S, Cohen DA, Finch BK et al. (2006) You are where you shop: grocery store locations, weight, and neighborhoods. Am J Prev Med 31, 10-17.

22. Hayes DK, Fan AZ, Smith RA et al. (2011) Trends in selected chronic conditions and behavioral risk factors among women of reproductive age, behavioral risk factor surveillance system, 2001-2009. Prev Chronic Dis 8, A120.

23. Kieffer EC, Sinco B \& Kim C (2006) Health behaviors among women of reproductive age with and without a history of gestational diabetes mellitus. Diabetes Care 29, 1788-1793.

24. US Department of Agriculture, Economic Research Service (2012) Food Environment Atlas. http://www.ers.usda.gov/ data-products/food-environment-atlas.aspx (accessed July 2012).

25. Zou G (2004) A modified Poisson regression approach to prospective studies with binary data. Am J Epidemiol 159, 702-706.

26. Evans AE, Jennings R, Smiley AW et al. (2012) Introduction of farm stands in low-income communities increases fruit and vegetable among community residents. Health Place 18, 1137-1143.

27. Ruelas V, Iverson E, Kiekel P et al. (2012) The role of farmers' markets in two low income, urban communities. J Community Health 37, 554-562.

28. Thornton L, Cameron A, McNaughton S et al. (2012) The availability of snack food displays that may trigger impulse purchases in Melbourne supermarkets. BMC Public Health 12, 194. 